\section{REVISTA TEMAS EM EDUCAÇÃO}

\section{"Até o sol torna-se quadrado"}

A propósito do livro de Maria

\author{
Salete van der Poel, Vidas
}

Aprisionadas: Relatos de uma

prática educativa (POEL,

2018)

\author{
Valeska Maria Fortes de Oliveira [*] \\ António Nóvoa [**]
}

[*] Doutora em Educação pela Universidade Federal do Rio Grande do Sul - UFRGS. Professora Titular no Departamento de Fundamentos da Educação da Universidade Federal de Santa Maria - UFSM. ORCID: https://orcid.org/0000-0002-8295-100 E-mail: vfortesdeoliveira@gmail.com

[**] Doutor em Ciências da Educação e História Moderna e Contemporânea. Professor catedrático do Instituto de Educação da Universidade de Lisboa e reitor honorário da mesma universidade.

ORCID: https://orcid.org/0000-0003-3171-1297

E-mail: novoa@reitoria.ulisboa.pt
1. O livro Vidas Aprisionadas é, acima de tudo, o registro da vida extraordinária da sua autora, Maria Salete van der Poel. Em todos os capítulos, é a sua história de "educadora popular militante transgressora" (POEL, 2019a, $\mathrm{s} / \mathrm{p}$ ), como ela própria se define, que nos é contada e apresentada - quando se refere à situação da educação no Brasil, ou às condições dos presídios, ou às práticas educativas em situação penitenciária, ou às histórias de vida dos presos...

$\mathrm{Na}$ sua trajetória de vida está uma parte importante da história da resistência à ditadura, das lutas pela liberdade e, sobretudo, dos movimentos de educação popular, a partir dos anos 1960. Este livro é um documento excepcional, pelas suas linhas e entrelinhas, que traduz a militância generosa de uma educadora que não entende a humanidade sem utopia: "Porque se eu perder a utopia eu perco a vida" (POEL, 2019b, s/p).

O momento marcante do seu envolvimento com a educação popular foi o encontro com Paulo Freire, em 1963, num Seminário em Recife, quando tinha 27 anos de idade: "Porque na minha vida teve o antes e o depois de Paulo Freire. Eu já era uma excelente alfabetizadora, mas o que me faltava era a ideologia, era a consciência política, era a militância, e isso eu só vim a descobrir depois de Paulo Freire" (POEL, 2019b, s/p). 
Este encontro com aquele que é, reconhecidamente, o mais importante educadorpedagogo mundial da segunda metade do século XX define toda a sua vida profissional. Salete van der Poel nunca mais deixará de aplicar, desenvolver e re-criar as perspectivas freireanas, afirmando mesmo, em entrevista recente, que Paulo Freire a "considerava a sua melhor discípula" (POEL, 2019b, s/p). Por isso, acompanhar o seu percurso é, também, compreender a forma como Paulo Freire foi sendo seguido, apropriado e reinventado na fase final da ditadura e nas primeiras décadas da democracia brasileira.

2. É impossível falar de Vidas Aprisionadas (POEL, 2018) sem uma referência ao seu livro-gêmeo, Alfabetização de adultos - Sistema Paulo Freire: Estudo de caso num presídio (POEL, 1981). Estes dois livros fazem parte de uma mesma experiência, levada a cabo pela autora entre 1978 e 1981, em presídios de João Pessoa. Alfabetização de adultos é a sua dissertação de mestrado, defendida em1979 (POEL, 1981). A atuação na Penitenciária Modelo de João Pessoa iniciou-se em julho de 1978 (POEL, 2018, p. 49), ainda que a apresentação ao diretor do Presídio tenha tido lugar apenas no dia 29 de agosto de 1978 (POEL, 2018, p. 34).

Nesta data, inicia-se um trabalho de educação popular, através da realização de um Círculo de Cultura no qual participaram, até ao final, 23 presos. Tudo se terá desenvolvido com grande intensidade, tanto a ação alfabetizadora como, paralelamente, a escrita da dissertação de mestrado, pois a autora explica-nos que, no dia 27 de novembro de 1978, já estava "escrevendo o último capítulo" e que, "em dezembro de 1978, a redação findara" (POEL, 2018, p. 243).

Em menos de quatro meses, Salete van der Poel não só conseguiu realizar uma notável experiência de educação popular, mas, acima de tudo, conseguiu finalizar uma dissertação de mestrado sobre esta mesma experiência. De acordo com a autora, tudo foi feito de forma sigilosa. Tanto a Universidade como os participantes no Círculo de Cultura só souberam que esta experiência constituía a base de uma dissertação de mestrado devido a uma reportagem publicada no jornal $O$ Norte, em 21 de Outubro de 1979: 
Mas o pior foi que ninguém sabia que eu estava fazendo a minha dissertação de mestrado no presídio. A notícia de uma reportagem em nada me ajudaria. Aconteceu exatamente como pensara. Caiu como uma bomba no Centro [Centro de Educação da Universidade Federal da Paraíba]. A reportagem "maldita", publicada no dia seguinte, tomou uma página inteira do jornal $O$ Norte. Foi aquele reboliço lá no Centro. Os(as) colegas do Mestrado e muitos(as) professores(as) ficaram incrédulos(as). Os(as) mais espirituosos(as), e havia muitos(as), saíram com "piadas". Algumas desagradáveis; outras, realmente engraçadas (POEL, 2018, p. $62)$.

Salete van der Poel explica também que estava curiosa em saber a reação dos educandos ao tomarem conhecimento, pelo jornal, de que a experiência em que participavam servia para uma dissertação de mestrado:

Foi um alívio quando cheguei ao presídio. Embora tivesse levado um exemplar do jornal, encontrei-os na sala debruçados sobre outro exemplar. [...] A turma estava se divertindo com as fotografias. Nunca os tinha visto com um sorriso tão escancarado e tão espontâneo. A gozação era bonita de ver... (POEL, 2018, p. 63).

Este caráter "sigiloso" tem de ser visto à luz da realidade política e acadêmica daquele tempo, o final dos anos 1970. Hoje em dia, seria impensável avançar para a realização e escrita de uma dissertação de mestrado sem as devidas autorizações acadêmicas e também não seria aceitável usar as atividades e as palavras dos participantes sem a sua autorização expressa. Salete van der Poel refere o cuidado que teve, e bem, na escolha dos presos que integraram o Círculo de Cultura, explicando o objetivo e a metodologia a utilizar na alfabetização: "Para nós, o mais importante seria a participação espontânea daqueles que quisessem, realmente, aprender a ler e escrever" (POEL, 1981, p. 50). Porém, não terá havido nenhuma informação sobre o fato de que a experiência seria relatada e analisada numa dissertação de mestrado.

As questões acadêmicas, que aqui trazemos, são uma parte importante dos livros de Salete van der Poel. No primeiro livro, naturalmente, pois trata-se da própria dissertação de mestrado. No segundo livro, publicado 37 anos mais tarde, é ainda a este tema que dedica as conclusões: "Percalços na trajetória acadêmica em tempos de repressão" (POEL, 2018, p. 234-250). São páginas muito reveladoras sobre o espaço universitário e os obstáculos colocados a estudos que tomassem Paulo Freire como inspiração. Paulo Freire não era somente uma bibliografia proibida nas Faculdades de Educação, como também os estudantes que ousassem reivindicar o estudo da sua obra eram taxados de comunistas, vistos como incomodativos e indesejados por muitos colegas e professores. Ter um livro de Paulo Freire 
nas mãos era um ato de rebeldia. É impossível separar estas dificuldades da situação política da ditadura brasileira, o que revela bem a coragem e a ousadia da autora.

Em 2018, Salete van der Poel ainda sente a necessidade de chamar a atenção para as perseguições e sofrimentos passados no período do Mestrado, em 1978-1979 e como, durante 40 anos, eles marcaram a sua vida. Objetivamente, a dissertação foi entregue em fevereiro de 1979 e foi defendida publicamente no dia $1^{\text {o }}$ de junho de 1979 (POEL, 2018, p. 243 e 247). Entretanto, em abril de 1979, o Centro de Educação da Universidade Federal da Paraíba abriu concurso para duas disciplinas, História da Educação Brasileira e Prática de Ensino de Sociologia da Educação, tendo Salete van der Poel sido aprovada nas duas, iniciando assim funções docentes universitárias (POEL, 2018, p. 123-124). As dificuldades em tomar posse nos concursos realizados mostravam as marcas deixadas pela ditadura, nos reconhecidos militantes dos movimentos de esquerda no Brasil.

Muitos docentes, até hoje, tendo perdido seus cargos de professores em algumas universidades brasileiras, não tiveram a reintegração posterior. A história que ainda não passamos a limpo (ANDES, 2018) com relação ao próprio trabalho iniciado nas Comissões Nacionais da Verdade, instituídas no país por ocasião dos governos populares, espera por ser contada. Como aponta Eliane Brum (2013, p. 417) no seu artigo "Memória é tanto lembrar quanto esquecer", tanto na esfera pessoal, quanto na pública, é uma escolha na esfera pública, a decisão de o que fazer com a memória, que está em jogo na Comissão Nacional da Verdade, apurar os crimes da ditadura. E é preciso lembrar - com todas as consequências implicadas nesse gesto - para que o país possa seguir adiante (BRUM, 2013).

O que poderia ser um semestre de realização pessoal e profissional para Salete van der Poel, acaba por ser recordado como um tempo muito duro, no qual as questões políticas e acadêmicas se cruzavam para dificultar uma pesquisa e uma ação, uma pesquisa-ação, que obviamente punha em causa o contexto autoritário da época. No final dos anos setenta e início dos oitenta no país, tivemos uma forte influência da pesquisa participante e da pesquisa-ação, especialmente desenvolvidas por estudantes de pós-graduação com militância política partidária ou em movimentos sociais. O contexto autoritário da época, ainda com muitas proibições e vigilâncias, mobilizava projetos silenciosos e cuidadosamente organizados a partir de outras ideologias. Nesse sentido, ganha força uma afirmação da autora sobre os 
problemas que viveu: "No fundo, de maneira diferente, estávamos TODOS presos" (POEL, 2018, p. 27).

3. O que importa destacar, pois é isso que junta os dois livros - Alfabetização de adultos (POEL, 1981) e Vidas aprisionadas (POEL, 2018) -, é um percurso pioneiro de intervenção educativa numa instituição carcerária. E, para mais, recorrendo a abordagens e metodologias de uma "educação para a libertação" (POEL, 1981, p. 30), a "uma prática alfabetizadora libertadora dentro de uma instituição total” (POEL, 2018, p. 19). A atualidade da leitura e da recuperação das duas produções da autora se reveste de significado no Brasil que violenta os direitos humanos e que tem figurado nos rankings mundiais nas denúncias de superlotação e maus tratos nas prisões. No meio de inúmeras citações recolhidas junto dos presos, algumas extraordinariamente eloquentes, escolhemos "Até o sol torna-se quadrado" (POEL, 2018, p. 59), para título desta resenha, pois ilustra a importância não só dos fatos, mas também do ponto de vista de quem os vê. Para estes presos, até o sol se tornou quadrado.

De fato, Salete van der Poel apresenta-se como "a pioneira da educação carcerária no Brasil" (POEL, 2019b, s/p), e é este o traço distintivo do seu percurso de vida, pelo menos na sua dimensão acadêmica. Assumir o risco de um trabalho deste tipo, no final dos anos 1970, diz-nos muito das suas convicções e da sua determinação. Toda a sua atividade é pautada por princípios de investigação-ação-participação, que são impossíveis de separar "para quem se dispõe a desenvolver uma prática educativa emancipatória” (POEL, 2019a).

O trabalho realizado com os 23 participantes do Círculo de Cultura da Penitenciária Modelo de João Pessoa segue de perto as propostas de alfabetização de Paulo Freire, obviamente adaptados a um contexto carcerário. Porém, a autora considera que o seu contributo original, se prende, como refere em várias passagens, com a forma como concebeu a avaliação das aprendizagens, considerando dois aspectos: "de um lado, o saber ler e escrever e, do outro, o processo de conscientização” (POEL, 1981, p. 32).

Em 2018, logo na dedicatória inicial do livro Vidas aprisionadas, a seu marido, Cornelis Joannes van der Poel, refere que a maior marca de 44 anos vividos em duelos de amor, cumplicidade e militância "foi a avaliação que criamos sobre a aplicação do Sistema Paulo Freire quando da realização da prática educativa no Presídio do Roger", para logo de seguida lamentar: "Interessante é que todos(as) os que têm lido o livro fizeram e fazem 
elogios. Porém, quanto ao tópico sobre a avaliação, com exceção dos Professores Jomard Muniz de Britto, Luiz Gonzaga e Alder Calado, ninguém, até hoje, se pronunciou. Há um estranho silêncio... Talvez seja difícil aceitar a diferença entre o ideal e o real, a aparência e a essência" (POEL, 2018, p.7).

A parte final do livro Alfabetização de adultos é dedicada à avaliação da experiência e, em particular, à avaliação da conscientização (POEL, 1981, p. 185-195). A autora parte dos trabalhos de Paulo Freire $(1978 ; 1979 ; 1984 ; 2001)$, definindo três níveis de conscientização:

\footnotetext{
Primeiro nível- Consciência intransitiva (imersão) ou "consciência real" Segundo nível- Consciência transitivo-ingênua (emersão) ou "consciência do inédito viável"

Terceiro nível- Consciência transitivo-crítica (inserção) ou "consciência, o máximo possível"
}

Estes três níveis são avaliados através de duas entrevistas aplicadas em torno de sete temas - direito de voto, lazer, religião, trabalho, direitos e deveres, estudo e situação vivencial -, antes e depois da ação de formação. A autora reconhece que "não é fácil avaliar o progresso que possa ter havido na experiência quanto à tomada de consciência" e que "é sempre difícil uma avaliação e classificação corretas de respostas a perguntas abertas" (POEL, 1981, p. 185 e 191). Para mais, toda a ação decorreu num período curto, de dois meses (POEL, 1981, p. 194), o que, obviamente, torna difícil avaliar os progressos na conscientização. Paulo Freire (1996, p. 26) vai dizer que "ensinar inexiste sem aprender e vice-versa e foi aprendendo socialmente que, historicamente, mulheres e homens descobriram que era possível ensinar. Foi assim, socialmente aprendendo, que ao longo dos tempos mulheres e homens perceberam que era possível, depois, preciso - trabalhar maneiras, caminhos, métodos de ensinar" (FREIRE, 1996, p.26).

$\mathrm{Na}$ verdade, não nos parece que o problema esteja apenas na dificuldade de proceder a esta avaliação, mas também na sua pertinência. A avaliação de processos subjetivos, marcados essencialmente por dinâmicas de apropriação pessoal, como é o caso da "tomada de consciência", talvez não possa mesmo ser objeto de uma avaliação externa, mesmo que esta tenha em conta a participação e reflexão de cada formando.

Aliás, o próprio Paulo Freire, em entrevista a Carlos Alberto Torres, em 1990, explica que, a partir de certo momento, deixou de utilizar o conceito de conscientização: 
Tive, indiscutivelmente, razões para desusar a palavra. Nos anos 70, com exceções, é claro, falava-se ou se escrevia de conscientização como se fosse ela uma pílula mágica a ser aplicada em doses diferentes com vistas à mudança do mundo. Mil pílulas para um patrão reacionário. Dez, para um líder sindical autoritário. Cinquenta pílulas para um intelectual cuja prática contradiz o discurso etc. etc. (FREIRE, 1991, p. 114)

As palavras de Paulo Freire são muito esclarecedoras quanto à necessidade "de diminuir os riscos abertosàs interpretações idealistas" que, segundo ele, foram ampliados pelo uso desregrado do conceito de conscientização. Ao colocar estes limites, está também a chamar a atenção para a "impossibilidade" de avaliar os progressos obtidos no que diz respeito à conscientização. Cada pessoa poderá fazer esta auto-avaliação no quadro do seu processo próprio de reflexão. Mas pretender organizar uma hétero-avaliação do "progresso no processo de conscientização", a cargo de um educador ou de um professor, parece um exercício de duvidosa oportunidade. Essa é também uma pretensão datada historicamente e, com várias reflexões críticas sobre as leituras e apropriações das produções de Paulo Freire.

4. Salete van der Poel é uma fabulosa contadora de histórias, como se torna evidente ao longo de Vidas aprisionadas. Desde logo, a história do próprio livro é deliciosamente bem contada. Diz-nos que, no dia 24 de outubro de 2015, recebeu em sua casa o Professor Agostinho Rosas e uma orientanda sua, interessada em fazer a dissertação num presídio de Recife:

\begin{abstract}
Algo aconteceu de especial naquela manhã. Enquanto eu e ela conversávamos, Agostinho ficou repassando uns cadernos e outros documentos que estavam em uma pasta deixada sobre a mesa. Tratava-se de uma velha pasta escura, capa dura, cheiro de mofo, guardada há quase 40 anos, morta e sepultada, escondida num canto interior da estante de difícil acesso. Durante todos esses anos, nunca retornada àquela pasta. Com o tempo, não só me desinteressei dela. Pior: esqueci-me de que existia. Também até hoje não compreendo por que, naquela manhã, a retirara de sua sepultura e a colocara sobre a mesa (POEL, 2018, p. 20).
\end{abstract}

O mistério da pasta escura vai dando origem a encontros e contatos, pondo em evidência que no seu interior estava um "tesouro", constituído por notas e registros da atividade desenvolvida em presídios, entre 1978 e 1981. Através de uma reflexão pessoal e de diálogos com vários colegas, a autora vai dando forma a estes apontamentos, escritos quase 40 anos antes, organizando-os para a publicação de um livro que contém duas partes 
principais: Diários de campo (POEL, 2018, p. 33-96) e Histórias de vida (POEL, 2018, p. 97 233). Essa experiência pode nos dizer muito, como pesquisadores da atualidade: quando trabalhamos com a produção de narrativas, ficamos com uma riqueza de material ainda para muitos trabalhos. A pasta da autora, recuperada por outros pesquisadores, atentos na leitura e sensíveis ao significado da retomada dos materiais, oportunizou nosso contato com outra produção dessa mulher de vida intensa, que é Salete van der Poel.

A primeira parte é constituída por uma série de "andanças pelo mundo dos presos". Salete van der Poel deixa-nos um retrato impressionante, admirável, da situação no Presídio de João Pessoa. Fala-nos da sua entrada nesta instituição, dos contatos com a direção, da maneira como, pouco a pouco, foi construindo o seu caminho e conquistando a confiança dos participantes no Círculo de Cultura e também de outros presos.

São páginas de uma leitura emocionante, nas quais se percebem as dificílimas condições de vida dos presos e a forma sensível e inteligente como a autora firmou o seu lugar e afirmou a sua legitimidade naquela instituição. Toda a narrativa é acompanhada por palavras dos presos, o que a torna mais efetiva e genuína. Na cartilha produzida no Círculo de Cultura, Aristarco, um dos presos, escreve:

Espero ver todo mundo fora dessa gaiola desumana, que é um espelho da gaiola maior onde estão os pobres, os oprimidos, os doentes e dos marginais que os homens exploradores criaram (POEL, 2018, p. 54).

Salete van der Poel relata muitos acontecimentos, alguns dramáticos, sobre a situação dos presos, os castigos a que estavam sujeitos, o dia em que o presídio amanheceu pichado com letras em preto e vermelho "Cadeia é o cemitério dos vivos", tentativas de fuga, a redação coletiva de um Manifesto e, sobretudo, esse dia 15 de novembro de 1978 em que houve um massacre: "O massacre do presídio do Roger faz parte de uma política deliberada e pensada de administração da morte, feita à base da omissão, descaso e perpetuação de condições medievais e de cumplicidade" (POEL, 2018, p. 89).

Este livro desfaz quaisquer dúvidas sobre o valor da literatura no campo da investigação educacional. E também sobre a importância da escrita, e de uma escrita elegante e atraente, para apresentar os trabalhos acadêmicos. 
Em todas as passagens, a autora defende os direitos humanos dos presos. Em vários momentos, cita a frase de um deles - "A gente sabe que errou. Ninguém aqui é santo" (POEL, 2018, p. 71) - mas isso não a impede de um olhar solidário, sensível e inteligente. A sua ação de educadora popular, em circunstâncias tão duras, merece o nosso elogio e admiração.

A segunda parte do livro, a mais longa, narra a história de vida de seis presos (cinco homens e uma mulher). Os cinco homens estão no Presídio do Roger, mas apenas três participaram no Círculo de Cultura. A mulher estava detida no Asilo do Bom Pastor, também em João Pessoa.

Não há, propriamente, um critério para a escolha destas seis histórias. Salete van der Poel dá-se a liberdade, e bem, de eleger as que lhe parecem mais interessantes e significativas. Esta liberdade decorre da legitimidade que a autora adquiriu através da sua própria história de vida e da sua trajetória como investigadora. Não se trata de recusar as regras acadêmicas e metodológicas habituais, mas de afirmar que elas não podem asfixiar a palavra, a liberdade e a qualidade narrativa dos autores.

Neste sentido, o livro Vidas aprisionadas é um excelente exemplo e uma lição, também na forma como as seis histórias de vida são contadas. Salete van der Poel não segue critérios pré-definidos, "apenas" dá lugar ao seu talento e imaginação para nos apresentar pessoas que vivem numa situação dramática. Mas neste "apenas" está verdadeiramente o que faz a diferença entre um trabalho com força explicativa e interpretativa e textos medíocres que pouco nos ajudam a pensar.

Neste momento, o método (auto)biográfico não tinha ainda emergido plenamente no campo acadêmico e, muito menos, na área da educação e da formação. Recorde-se que um dos textos iniciais que relançou as abordagens biográficas foi publicado por Franco Ferrarotti em 1979, Sobre a autonomia do método biográfico (NÓVOA; FINGER, 1988). Nele, fala-se das mediações, das subjetividades e do "universal singular".

A intuição de Salete van der Poel leva-a a antecipar muitas evoluções que só viriam a dar-se posteriormente. Não estamos tanto perante as abordagens autobiográficas ou das histórias de vida, tal como se viriam a popularizar nos anos 80/90 (NÓVOA, 1995), mas sobretudo face a uma narrativa literária que, a partir dos diálogos com os presos, se estrutura com acontecimentos, transcrições das falas e comentários diversos. A autora autoriza-se a 
contar livremente estas histórias, sempre com o objetivo de que elas se constituam como um "espaço de libertação" e aproximação das experiências vividas pelos sujeitos.

Não é este o lugar para descrever estas seis histórias: de Boanerges (POEL, 2018, p. 98-114), de Teudas (POEL, 2018, p. 115-120), de Joacaz (POEL, 2018, p. 120-130), de Mosoc (POEL, 2018, p. 130-140), de Salomão (POEL, 2018, p. 140-161) e de Divina Zelfa (POEL, 2018, p. 162-233). Há traços comuns nestas histórias - a desesperança é talvez o principal. E, no entanto, algumas têm desfechos felizes.

As narrativas afastam-se muito da experiência educativa apresentada no primeiro livro, Alfabetização de adultos. Agora, a atenção de Salete van der Poel centra-se, por inteiro, nas histórias de cada uma das pessoas com quem se relaciona. A sua dedicação e a sua entrega são plenas. De tal maneira que Thimoty D. Ireland afirma, na apresentação da obra, datada de Março de 2018, que estas histórias de vida "extrapolam o material original à medida que Salete continuava e continua acompanhando a vida dessas pessoas até o presente ou, em alguns casos, até a sua morte" (Timothy D. Ireland, in POEL, 2018, p. 14).

Talvez o que melhor caracteriza a experiência narrada por Salete van der Poel seja a ideia de vínculo. Em todos os momentos, é esta a palavra certa para definir o compromisso da autora como educadora popular. E este vínculo vai tão longe que, segundo refere, as conversas prolongavam-se por muitos momentos. No caso de Zelfa, "nunca deixou o Clube [de Leitura] e continuava participando, só que saía mais cedo para nossa terapia, como passei a chamar" (POEL, 2018, p. 183). E não era só com Zelfa que se concretizava uma interação quase terapêtica...

Este vínculo dá força a uma narrativa que nunca é neutra ou indiferente. Salete van der Poel afirma as suas posições e não esconde os seus propósitos. Não há distância na sua escrita, há compromisso e encantamento. Talvez, uma outra palavra que fala dessa prática comprometida seja 'implicação'. A autora implica-se com as pessoas e suas narrativas. É isso que nos atrai na sua escrita e no seu percurso. As últimas palavras desta resenha pertencemlhe, por direito próprio:

Por mais incrível que pareça, passei dias mágicos no Presídio do Roger. Em nenhum outro lugar fui tão respeitada como dentro daquele abismo de atrocidades. Lá encontrei sofrimento e beleza de maneira pungente e viva,

afora a delicadeza da nossa amizade. Pode ser que muitos(as) não acreditem no que estou dizendo. Vi muita beleza ali dentro. Aqueles homens que participaram do 
Círculo de Cultura viveram na sarjeta, andaram por caminhos tortuosos, afastaram muitos espinhos, tiveram uma dura experiência de viver, mas não se tornaram homens ácidos. Ao contrário. Muitos colocaram belezas nas maldades. Outros mostraram ser feitos de outras matérias: resistência, afirmação, libertação. Meu fascínio por cada um estava nos seus talentos para arriscar, enfrentar, lutar, desafiar e dar inclusive suas próprias vidas (POEL, 2018, p. 29).

A obra Vidas Aprisionadas é um convite para conhecer narrativas de pessoas que o vivido foi privando de olhar o sol na sua generosidade, mas ainda a importância da escuta sensível, da implicação e do vínculo de um trabalho educacional de uma mulher militante que potencializou o legado de Paulo Freire.

\section{REFERÊNCIAS}

ANDES - SN. Atitudes de rebeldia: as formas da universidade tecnocrática, o aparato vigilante - repressivo e as resistências dos professores da UFF durante a ditadura. Associação dos Docentes da Universidade Federal Fluminense - Seção Sindical do ANDES SN. Rio de Janeiro: Usina Editorial, 2018.

BRUM, Eliane. A menina quebrada e outras colunas de Eliane Brum. Porto Alegre: Arquipélago Editorial, 2013.

FREIRE, Paulo. A educação na cidade. São Paulo, Cortez Editora, 1991.

FREIRE, Paulo. Ação cultural para a liberdade e outros escritos. 3. ed. Rio de Janeiro: Paz e Terra, 1978.

FREIRE, Paulo. Conscientização. São Paulo, Cortez \& Moraes, 1979.

FREIRE, Paulo. Educação como prática da liberdade. 15. ed. Rio de Janeiro: Paz e Terra, 1984.

FREIRE, Paulo. Pedagogia da Autonomia. 2a. ed. São Paulo: Paz e Terra, 1996.

FREIRE, Paulo. Pedagogia do Oprimido. 30. ed. Rio de Janeiro: Paz e Terra, 2001.

NÓVOA, António. Vidas de professores. Porto, Porto Editora, 2. edição, 1995.

NÓVOA, António; FINGER, Matthias (Org.). O método (auto)biográfico e a formação. Lisboa, Ministério da Saúde, 1988.

POEL, Maria Salete van der. Alfabetização de adultos - Sistema Paulo Freire. Estudo de caso num presídio. Petrópolis, Vozes, 1981. 
POEL, Maria Salete van der. Vidas Aprisionadas- Relatos de uma prática educativa, São Leopoldo, Oikos, 2018.

POEL, Salete van der. "Escrevivendo a liberdade: O papel da literatura nas prisões", VI

Congresso Nacional de Educação. 2019a. Disponível em $<$ https://www.editorarealize.com.br/revistas/conedu/trabalhos/TRABALHO_EV127_MD1_S A17_ID8309_25112019164029.pdf>. Acesso em: 15 mai. 2020.

POEL, Maria Salete van der. Se eu perder a utopia, eu perco a vida, diz Maria Salete van der Poel. [Entrevista disponibilizada em 26 de junho de 2019b.] Disponível em: $<$ https://www.extraclasse.org.br/educacao/2019/06/se-eu-perder-a-utopia-eu-perco-a-vida $>$. Entrevista concedida a Cristiano Goldschmidtv. Acesso em: 15 mai. 2020.

Para além das obras indicadas, consultar também dois vídeos:

- Vermelha por dentro, entrevista de Samara Mello a Salete van der Poel, João Pessoa, 2016 (http://memoriasdeverdade.blogspot.com/2016/07/vermelha-por-dentro.html).

- Repressão e Resistência na Paraíba - Maria Salete van der Pöel e Ana Rita Castro (https://www.youtube.com/watch?v=r16BdafPf7E).

$8^{\mathrm{a}}$ sessão de depoimentos de perseguidos pela ditadura militar, realizada em 31.03.2011, Auditório da Central de Aulas/UFPB, Coordenação: Rosa Maria Godoy Silveira.

Submetido em: maio de 2020.

Aprovado em: julho de 2020.

Publicado em: julho de 2020. 